\title{
Diálogos sobre o currículo da formação inicial de professores de matemática: narrativas discentes
}

\author{
Cleber Dias da Costa Neto ${ }^{1}$ \\ Victor Giraldo ${ }^{2}$
}

\section{RESUMO}

Este trabalho investiga o currículo da Licenciatura em Matemática de uma perspectiva dos discentes desse curso na Universidade Federal do Rio de Janeiro. Analisamos episódios selecionados dos dados produzidos em uma roda de conversa com doze participantes, egressos e estudantes do curso. Buscamos responder às questões acerca das percepções desses atores sobre como suas práticas são constituídas pelo currículo do curso, relacionandoas com as formas por meio das quais suas ações como discentes têm um papel na construção desse currículo. A metodologia utilizada baseou-se em um processo de re-storying (NARDI, 2016), por meio do qual identificamos episódios, analisados em diálogos ficcionais entre personagens, sob um prisma teórico de narrativas (BARBOSA, 2015), formação de professores (TARDIF, 2013; NÓVOA, 2009; COCHRAN-SMITH, LYTLE, 1999; MOREIRA, 2012) e currículo (LOPES, 2013; GABRIEL, 2013; SILVA, 2014). Nossa análise revela percepções, consensos e contradições dos participantes sobre o currículo da Licenciatura em Matemática na Instituição.

PALAVRAS-CHAVE: Currículo. Formação de Professores de Matemática. Narrativas. Diálogos Discentes.

Dialogues on the curriculum of pre-service mathematics teachers education: students' narratives

\footnotetext{
${ }^{1}$ Doutor. Universidade Federal do Rio de Janeiro, Rio de Janeiro, RJ, Brasil. https://orcid.org/0000-0001-7801-8591. cleberneto@gmail.com.

${ }^{2}$ Doutor. Universidade Federal do Rio de Janeiro, Rio de Janeiro, RJ, Brasil. https://orcid.org/0000-0002-2246-6798. victor.giraldo@gmail.com.
} 


\begin{abstract}
This paper investigates pre-service mathematics teachers education curricula, from a standpoint of students of this programme at the Federal University of Rio de Janeiro. We analyze episodes selected from data produced in a discussion group with twelve participants, former and current students of the programme. We seek to answer questions concerning their perceptions on how their practices are constituted by the curriculum, linking these perceptions with the ways through which their actions as students play a role on shaping the curriculum. Our methodology is based on a re-storying process (NARDI, 2016), through which we identify episodes, build and analyze fictional dialogues among characters, under a theoretical frame of narratives (BARBOSA, 2015), teachers education (TARDIF, 2013; NÓVOA, 2009; COCHRAN-SMITH, LYTLE, 1999; MOREIRA, 2012) and curriculum (LOPES, 2013; GABRIEL, 2013; SILVA, 2014). Our analysis reveals participants' perceptions, consensus and contradictions on the curriculum of the preservice mathematics teachers' education programme at the Institution.
\end{abstract}

KEYWORDS: Curriculum. Mathematics teachers' education. Narratives. Students dialogues.

\title{
Introdução
}

Este trabalho é parte de uma pesquisa mais ampla, correspondente à tese de doutorado do primeiro autor com supervisão do segundo, cujo objetivo geral é investigar o currículo do curso de Licenciatura em Matemática da Universidade Federal do Rio de Janeiro (UFRJ) a partir da década de 1980. Tal pesquisa mais ampla se dá sob as perspectivas: (i) da instituição e seus documentos oficiais sobre o curso; (ii) dos docentes desse curso; e (iii) dos estudantes e egressos do curso. Este texto enfoca a última perspectiva. As duas primeiras foram abordadas em outros trabalhos. Neste artigo, relatamos uma investigação sobre o currículo da Licenciatura em Matemática da UFRJ, a partir do olhar de sujeitos que foram ou são estudantes do curso, com base 
na premissa de que estes têm suas práticas docentes e concepções sobre a profissionalização da docência constituídas, em certa medida, pelos percursos construídos durante a formação inicial, conforme sugere a literatura de pesquisa em formação de professores (e.g. TARDIF, 2013; NÓVOA, 2009; COCHRAN-SMITH e LYTLE, 1999).

Para investigar a perspectiva discente, utilizamos como instrumento metodológico uma roda de conversa, com um processo de reestruturação dos dados produzidos, inerentemente ligado à natureza narrativa da pesquisa. Tal processo constitui uma forma não convencional de organização e análise de dados, que rompe "com a representação tradicional da pesquisa" (BARBOSA, 2015). Analisaremos, assim, episódios selecionados dos dados produzidos a partir da roda de conversa, buscando responder às seguintes questões: Como as percepções de estudantes e de egressos de um curso de Licenciatura em Matemática sobre suas próprias práticas são constituídas pelo currículo de sua formação inicial? Como suas ações como discentes podem participar da construção desse currículo? Antes de avançarmos no detalhamento da metodologia e na análise dos dados, procedemos com uma discussão teórica sobre formação de professores, currículo e narrativas.

\section{Formação de Professores, Currículo e Narrativas}

No Brasil, o debate teórico sobre formação docente em matemática ocorre de maneira mais sistematizada desde os anos 1980. No contexto da UFRJ, isso se evidencia nas reformas curriculares da Licenciatura em Matemática, que assumem características dos modelos associados às alcunhas $3+1$ e quase tricotomia na literatura de pesquisa brasileira. Moreira (2012) descreve o modelo 3+1 como aquele segundo o qual a formação docente se estrutura em blocos correspondentes a conhecimentos matemáticos e pedagógicos, separados nos três anos iniciais e ano final do curso, respectivamente. Fiorentini e Oliveira (2013) propõem o termo quase tricotomia como uma reconfiguração do $3+1$, caracterizada pela separação em três blocos: formação matemática, formação didático-pedagógica e prática 
profissional, sendo o último constituído por disciplinas supostamente voltadas ao ensino de matemática na escola. Ambos os termos, $3+1$ e quase tricotomia, se relacionam com a discussão proposta por Shulman (1986), sobre os conhecimentos necessários ao professor para sua prática docente.

Recentemente, a prática como componente curricular, eixo estruturante dos marcos legais das Licenciaturas no Brasil (e.g. BRASIL, 2015), vem ganhando destaque nos debates sobre políticas de formação de professores e, consequentemente, tem sido tema central em espaços e eventos em que se discute o currículo da Licenciatura em Matemática da UFRJ. Exemplos desse tipo de espaço estão nos Seminários da Licenciatura em Matemática, eventos organizados pelo Programa de Pós-Graduação em Ensino de Matemática da UFRJ para debater a formação inicial de professores de matemática na Instituição, que já contam com cinco edições desde 2013 (PEMAT, 2016). O recente debate sobre a prática como componente curricular no contexto brasileiro pode se relacionar com tendências de pesquisa que destacam saberes produzidos a partir da prática, em uma perspectiva de profissionalização docente (e.g. TARDIF, 2013), que consideram o professor da educação básica como ator central na formação docente (e.g. NÓVOA, 2009) e que defendem a não dicotomização entre conhecimentos teóricos e práticos (e.g. COCHRAN-SMITH e LYTLE, 1999). A nosso ver, esse debate também envolve uma defesa da especificidade de saberes docentes sobre o conteúdo, que pode indicar caminhos para que a formação docente seja estruturada a partir de uma epistemologia da prática.

Consideramos que professores de matemática formados pela UFRJ nos últimos 40 anos podem ter suas práticas e concepções constituídas pelos modelos 3+1 e quase tricotomia, identificados na Instituição em Costa-Neto e Giraldo (2019). Discussões recentes sobre prática como componente curricular também podem constituir a formação desses sujeitos, mesmo sem se materializarem em programas curriculares, uma vez que, assim como Oliveira e Lopes (2011), entendemos que currículos não se configuram apenas por textos, mas também por discursos. Esses movimentos nos currículos de 
formação de professores de matemática podem ter relações com disputas políticas entre matemáticos e educadores matemáticos - não necessariamente pelo protagonismo na formação docente (em matemática) -, que, como observa Gabriel (2013), tendem a se relacionar com diferenças nos campos de atuação, no reconhecimento pela comunidade científica e na filiação a áreas de pesquisa. Porém, as teorias curriculares pós-críticas sugerem que a complexidade desse debate transcende os binarismos entre matemáticos e educadores matemáticos. Isto é, essas teorias reexaminam as conexões entre currículo e poder destacadas nas teorias críticas (LOPES, 2013) que, invariavelmente, centram a análise em antagonismos dos quais buscamos aqui fugir. No contexto da Licenciatura em Matemática da UFRJ, verificamos em Costa-Neto e Giraldo (2019) que análises baseadas apenas em dicotomias e tensões macropolíticas entre Matemática e Educação Matemática nem sempre são suficientes para explicar a micropolítica envolvendo as relações e disputas entre docentes e departamentos.

Abre-se, então, espaço para que, além de enfocar em uma dimensão mais ampla da formação docente, utilizemos procedimentos metodológicos que permitam explorar relações capilares que se articulam e constituem as micropolíticas relativas ao currículo da Licenciatura em Matemática da UFRJ. Assim, recorremos a narrativas de atores que podem estar invisíveis ao foco macropolítico. Vários pesquisadores brasileiros, baseados nos trabalhos de Stephen Ball, entendem políticas curriculares como sendo constituídas por um conjunto de textos e de discursos localizados dentro de uma rede, sendo dependentes de contextos históricos e de poder e tendo seus sentidos modificados pelos fluxos desses textos e discursos de um contexto para outro (OLIVEIRA e LOPES, 2011). Ainda, como proposto por Silva (2014) ao destacar o currículo como currere (percurso), entendemos que o currículo se realiza de formas diferentes para cada sujeito. Portanto, os discursos dos estudantes egressos e atuais do curso podem evidenciar novas questões sobre seu currículo, em um contexto de mudanças nos programas curriculares (textos) promovidas pelo corpo docente (outros discursos). 
Assim, a construção de narrativas discentes, destacando seus percursos diversos e protagonismos nesse cenário, é nosso foco neste artigo. Como Cury et al. (2014), consideramos que tais textos possibilitam apropriações do conteúdo por parte do leitor, que pode se tornar vetor de novas narrativas repassadas a terceiros. Neste caso, o conteúdo é o currículo da Licenciatura em Matemática da UFRJ, entendido como sendo constituído de múltiplas narrativas, inclusive das que não são hegemônicas e carecem de visibilidade (SILVA, 2014). Esse processo, que pode levar à desconstrução de narrativas hegemônicas, é viabilizado a partir da "valorização dos depoimentos, da voz daqueles que colaboram na pesquisa educacional", ao mesmo tempo que libera o leitor "para construir suas próprias interpretações" (BARBOSA, 2015, p. 359). Barbosa (2015) destaca também que narrativas podem ser expressas em formas e gêneros literários variados: como biografias, dramas, entrevistas, ou qualquer criação, ficcional ou não. Passamos a descrever o processo metodológico de estruturação de uma narrativa possível, não hegemônica, sobre o currículo da Licenciatura em Matemática da UFRJ a partir de diálogos entre discentes do curso. Em seguida, apresentamos os resultados e, por fim, considerações sobre os dados produzidos.

\section{Da roda de conversa à reestruturação dos dados}

Relatamos aqui a estrutura metodológica da pesquisa, destacando os instrumentos utilizados, a organização e a apresentação dos dados, bem como as referências teórico-metodológicas que embasaram essa estrutura, sem separá-los em etapas de coleta, tratamento e análise de dados. Entendemos que o procedimento de análise perpassa por todas as ações que descrevemos, desde as escolhas iniciais até as releituras finais do texto.

Em setembro de 2018, organizamos uma roda de conversa. Participaram doze sujeitos, sendo três estudantes que cursavam a Licenciatura em Matemática na UFRJ e estavam no $1^{\circ}, 3^{\circ}$ e no último anos da formação; e nove egressos, que haviam sido estudantes do curso entre 1984 e 2016. A roda de conversa foi mediada por nós, autores, e como fomos 
estudantes da instituição e colegas de vários dos participantes, assumimos uma posição mais horizontal em relação a eles. Além disso, ambos somos docentes da UFRJ, em unidades acadêmicas corresponsáveis pelo curso de Licenciatura em Matemática, o Colégio de Aplicação (CAp-UFRJ) e o Instituto de Matemática (IM-UFRJ). Assim, nossa atuação como mediadores tem potencial de deslocamento dos discursos na roda de conversa, pois nossas concepções sobre formação de professores de matemática podem ser conhecidas pelos participantes em virtude de nossas posições como colegas ou formadores de alguns deles. Não nos colocamos, portanto, como externos e isentos à pesquisa. Ao contrário, assumimos esse enviesamento como parte constituinte e aspecto metodológico central da investigação. Entendemos que esse tipo de influência também se dá em outros contextos e não prejudica a investigação, pois os procedimentos metodológicos que adotamos consideram que tais influências fazem parte da construção dos discursos.

O quadro 1 apresenta dados gerais dos participantes, que concordaram com os termos de confidencialidade e terão suas identidades pessoais mantidas em sigilo. Para cada participante, são apontadas informações sobre idade; gênero; anos de ingresso e conclusão do curso de Licenciatura em Matemática da UFRJ; local de atuação profissional atual; e formação em pósgraduação stricto sensu com área, anos de ingresso e conclusão do(s) curso(s). O participante G não concluiu o curso na UFRJ e os participantes $\mathrm{J}, \mathrm{K}$ e L ainda eram estudantes. Os participantes J e K não atuavam regularmente como docentes, e a participante L é professora dos anos iniciais do ensino fundamental, por formação anterior. 
QUADRO 1: Dados gerais sobre os participantes da roda de conversa.

\begin{tabular}{|c|c|c|c|c|c|c|c|c|c|c|c|}
\hline \multirow{2}{*}{ Participantes } & \multirow{2}{*}{\begin{tabular}{l|} 
Idade \\
(anos)
\end{tabular}} & \multirow{2}{*}{ Gênero } & \multicolumn{2}{|c|}{ Licenciatura - UFRJ } & \multirow{2}{*}{$\begin{array}{c}\text { Atuação } \\
\text { Profissional } \\
\end{array}$} & \multicolumn{3}{|c|}{ Mestrado } & \multicolumn{3}{|c|}{ Doutorado } \\
\hline & & & \begin{tabular}{|l|} 
ingresso \\
\end{tabular} & \begin{tabular}{|l|} 
conclusão \\
\end{tabular} & & área & ingresso & conclusão & área & ingresso & onclusão \\
\hline A & 52 & $\mathrm{~F}$ & 1984 & 1990 & Escola Federal & Matemática & 1997 & 2000 & Educação Matemática & 2014 & 2018 \\
\hline B & 48 & M & 1989 & 1993 & Escola Federal & Matemática Aplicada & 2003 & 2005 & História da Matemática & 2007 & 2011 \\
\hline $\mathrm{C}$ & 47 & F & 1989 & 1992 & Escola Municipal & Matemática & 1995 & 1998 & & & \\
\hline D & 45 & M & 1993 & 2008 & Escola Federal & Educação Matemática & 2006 & 2009 & & & \\
\hline E & 49 & M & 1993 & 2002 & \begin{tabular}{|l|} 
Escola Estadual e \\
Escola Federal (Temporário)
\end{tabular} & Matemática (Profissional) & 2014 & 2016 & & & \\
\hline $\mathrm{F}$ & 39 & M & 1999 & 2005 & Escola Municipal & Educação Matemática & 2006 & 2008 & & & \\
\hline G & 36 & M & 2002 & & Escola Estadual & & & & & & \\
\hline $\mathrm{H}$ & 34 & M & 2003 & 2007 & $\begin{array}{l}\text { Escola Municipal e } \\
\text { Escola Privada }\end{array}$ & História da Matemática & 2008 & 2011 & & & \\
\hline I & 25 & M & 2012 & 2016 & $\begin{array}{l}\text { Escola Federal (Temporário) } \\
\text { e Escola Privada }\end{array}$ & & & & & & \\
\hline $\mathrm{J}$ & 23 & $\mathrm{~F}$ & 2015 & & & & & & & & \\
\hline K & 21 & M & 2016 & & & & & & & & \\
\hline $\mathrm{L}$ & 20 & $\mathrm{~F}$ & 2018 & & Escola Privada & & & & & & \\
\hline
\end{tabular}

Fonte: autores.

O debate foi estimulado por um roteiro estruturado em cinco questões (quadro 2). Cada uma das questões contou com intervenções de pelo menos metade dos participantes, que não se limitaram a respostas para as perguntas, pois emergiram consensos, dissensos, rememorações, em que os participantes interagiram entre si e com os entrevistadores, evidenciando uma pluralidade de posicionamentos. A roda de conversa durou quase três horas, gravadas em áudio e em vídeo.

QUADRO 2: Questões do roteiro da roda de conversa

1 - Façam uma breve apresentação pessoal (nome, período no qual cursou, formação em pós-graduação, atuação profissional)

2 - O que acham do currículo da Licenciatura em Matemática da UFRJ que vocês cursaram ou cursam?

3 - Quais disciplinas da grade curricular vocês identificam como mais importantes para suas ações profissionais na docência (atuais ou futuras)? Por que?

4 - Existem disciplinas da grade curricular que vocês identificam como desnecessárias para a formação do professor de matemática? Se sim, quais?

5 - Como seria um currículo de Licenciatura em Matemática ideal para formar um profissional que ensina matemática na educação básica?

Fonte: autores.

A roda de conversa gerou muitas falas, com simultaneidades e atravessamentos, o que dificultaria sua transcrição na íntegra. Além disso, nossa unidade de análise está na coletividade de discentes, e não nos sujeitos 
individualmente. Assim, optamos por um processo de organização e reestruturação dos dados, que delineamos a seguir. Primeiramente, selecionamos eventos críticos, a partir das gravações da roda de conversa. Inspirados em Powell et al. (2004), consideramos eventos críticos como momentos em que ocorrem dissensos entre os participantes; divergências em relação a dados de documentos ou de depoimentos de docentes, obtidos em outras partes da pesquisa mais ampla da qual este trabalho se insere (COSTA-NETO e GIRALDO, 2019); ou percepções que dialogam com a literatura, confirmando ou contradizendo hipóteses de pesquisa. Em seguida, procedemos uma organização sistemática de dados, em quatro fases, com inspiração em Lima (2015): (1) descrever os eventos críticos; (2) transcrever os eventos críticos; (3) discutir os dados; (4) limpar as transcrições, que também se baseou em Powell et al. (2004). Assim, selecionamos eventos críticos, descritos em pequenos textos, conforme o exemplo a seguir, o que foi ponto de partida para a organização dos dados de forma entrelaçada.

\section{Descrição do Evento Crítico X}

(1:35:30) Perguntamos ao Egresso 1 sobre a parcela de responsabilidade do estudante no currículo do curso, após Egresso 1 ter apontado que a culpa é da instituição, dos professores e dos estudantes. Ele argumenta que o estudante de Licenciatura em Matemática é muito passivo e relata um episódio que ilustra uma possibilidade de ação. (1:38:10)

Como o exemplo ilustra, destacamos os momentos da gravação em que o evento se inicia e se encerra. O fato de não termos o compromisso de transcrição literal de todos os dados nos conferiu maior liberdade para conectar os eventos críticos, em um processo inicial de análise. Em seguida, passamos à transcrição literal na íntegra de cada evento selecionado, registrando todas as falas audíveis e indicando os momentos em que o entendimento não era possível. Desta forma, acessamos as falas, bem como concordâncias e discordâncias dos participantes, expressas por burburinhos e falas sobrepostas. Os registros dessas percepções foram peças-chave para a apresentação dos dados. Por fim, as fases "discutir os dados" e "limpar as 
transcrições" propostas por Lima (2015) foram adaptadas em um processo de reestruturação dos dados.

Para esse processo, nos inspiramos na abordagem narrativa de restorying que consiste na construção de uma "história a partir dos dados originais" com base em "elementos narrativos como o problema, personagens, cenário, ações e resolução" (NARDI, 2016). No nosso caso, a partir das transcrições, construímos novas histórias sobre o olhar discente acerca do currículo da Licenciatura em Matemática da UFRJ. Entendendo que toda forma de análise é uma releitura, contamos nessas novas histórias com diálogos entre personagens ficcionais: quatro discentes e um mediador.

Os personagens discentes foram caracterizados com base em aproximações entre os participantes. Suas falas foram construídas a partir do entrelaçamento das falas originais. As falas do mediador foram inseridas nos novos diálogos para conectar falas dos demais personagens e como forma de trazer elementos das experiências dos autores como estudantes e docentes da instituição. Não procuramos construir personagens isentos de contradições, por entender que narrativas, mesmo no discurso de um único sujeito, acessam sentidos e afetos que emergem no debate (BARBOSA, 2015, p. 359). Assim, o procedimento de Lima (2015) combinado com elementos do re-storying (NARDI, 2016) compuseram nossas bases teórico-metodológicas.

\section{Resultados: caracterizações dos personagens e episódios}

Em lugar da convencional determinação de categorias de análise, apresentamos os dados produzidos por meio de um processo de reestruturação de diálogos da roda de conversa. O quadro 3 a seguir mostra as caracterizações dos personagens ficcionais discentes. Usamos os pseudônimos Marta, Hélton, Roberto e Juninho, sendo o primeiro feminino e os demais masculinos, conforme a proporção dos participantes na roda de conversa. Utilizamos o termo Mediador para o personagem que representa os autoresmediadores com falas que estiveram presentes na roda de conversa ou que são frutos do processo de análise e interpretação dos dados. 
Cada personagem incorpora múltiplas referências às identidades reveladas, não se referindo a um único participante. Suas caracterizações nos permitiram refletir sobre a complexidade dos fluxos de sentidos que atravessam os sujeitos, como potencialmente constituídos e participantes da construção dos currículos. Integramos essa complexidade na caracterização, pois não buscamos criar personagens definidos por consistência de visões ou por isenção de contradições a partir de algum julgamento a priori. Tal processo colaborou ainda para acessarmos relações do currículo do curso com as trajetórias dos futuros professores a partir de experiências em diferentes contextos. Para a caracterização, usamos como critérios o período em que foram estudantes, a formação de pós-graduação e a prática profissional.

QUADRO 3: Caracterizações dos personagens discentes

\begin{tabular}{|c|c|}
\hline Personagem & Caracterização \\
\hline Marta & $\begin{array}{l}\text { Estudante do curso de } 1987 \text { a } 1991,50 \text { anos. Cursou Mestrado em } \\
\text { Matemática e Doutorado em Educação Matemática. Lecionou em } \\
\text { escolas privadas e públicas do Rio de Janeiro, foi docente em } \\
\text { cursos de Licenciatura e hoje é professora de escola pública } \\
\text { federal. }\end{array}$ \\
\hline Hélton & $\begin{array}{l}\text { Estudante dos cursos de Bacharelado e Licenciatura em } \\
\text { Matemática de } 1996 \text { a } 2002 \text {, tem } 42 \text { anos e cursou Mestrado em } \\
\text { Educação Matemática. Atualmente, leciona em escolas privadas e } \\
\text { públicas da cidade do Rio de Janeiro. }\end{array}$ \\
\hline Roberto & $\begin{array}{l}\text { Estudante do curso de } 2003 \text { a } 2010,34 \text { anos. Migrou para uma } \\
\text { instituição privada de ensino superior para concluir a } \\
\text { Licenciatura em Matemática. Atualmente, é professor e diretor de } \\
\text { escola pública estadual do Rio de Janeiro. }\end{array}$ \\
\hline Juninho & $\begin{array}{l}\text { Estudante do curso desde } 2015,23 \text { anos. Está no ano de conclusão } \\
\text { do curso e realizou parte da graduação em intercâmbio em umá } \\
\text { universidade fora do país com subsídio do governo federal. É } \\
\text { formado, em curso de nível médio, como professor dos anos iniciais } \\
\text { do ensino fundamental e leciona em uma escola privada. }\end{array}$ \\
\hline
\end{tabular}

Fonte: autores.

Exibimos os diálogos reestruturados a partir dos eventos críticos, identificados em 3 episódios. Cada episódio aborda o tema de um ou mais eventos críticos, considerados relevantes para responder a nossa questão de pesquisa. Informações de eventos críticos secundários, ou seja, falas que não versam diretamente sobre o tema abordado num episódio, podem figurar 
como elementos constituintes desses diálogos e, assim como o conteúdo das falas do mediador, podem trazer considerações realizadas durante a roda de conversa ou representar análises posteriores. A construção dos diálogos reestruturados possibilitou ainda a inserção do contraditório em sequências de falas que originalmente não apresentavam confrontos de ideias de maneira explícita. Apontamos antecipadamente algumas características, não as únicas, do formato metodológico da apresentação dos dados: entrelaçamento entre eventos que se relacionam na roda de conversa ou com os referenciais teóricos; múltiplas versões sobre um mesmo episódio; inserção de inferências dos mediadores como elementos analíticos; não-linearidade do processo metodológico. Assim, reforçamos a ligação intrínseca do processo metodológico com a natureza do conteúdo discutido, ao propiciar uma multiplicidade de narrativas ou ao dar protagonismo às ações em relação à constituição do currículo, como defende Silva (2014).

Apresentamos, em sequência, os 3 episódios, na ordem cronológica em que os construímos. Escolhemos esse critério por utilizarmos em um mesmo episódio elementos de eventos críticos percebidos em momentos distintos da roda de conversa, e também buscando sermos fieis à sequência de temas identificados como relevantes ao longo do processo metodológico.

\section{Episódio 1: Da passividade à ação.}

Mediador: Como seria um currículo de Licenciatura em Matemática ideal para formar um profissional que ensina matemática na educação básica?

Hélton: É complexa a resposta, porque eu acho que, em relação ao currículo, os professores e os alunos são tão responsáveis quanto à instituição.

Mediador: Têm o mesmo grau de responsabilidade?

Hélton: Praticamente. A instituição está errada porque quando percebe que a formação não está adequada aos desafios da docência, tenta resolver propondo um novo currículo. Porém, este ainda está dentro da mesma estrutura.

Marta: Isso é verdade. O currículo da minha época não tem muita diferença para o atual.

Hélton: Já os professores, ao invés de dar a ementa da disciplina, falam só sobre o que pesquisam e abordam o que estão afim e mandam os estagiários de pós-graduação 
darem as aulas.

Marta: Existem vários que fazem isso, desde quando estudei lá.

Juninho: Tem até hoje. No último semestre mesmo, tive um caso desse. E o pior era que a correção das avaliações desse professor não tinha meio termo. Era tudo certo ou tudo errado.

Hélton: O problema é que depois o estudante, futuro professor, vai reproduzir essa lógica na escola.

Mediador: É nesse ponto que está a responsabilidade do estudante do curso com o currículo?

Hélton: Um pouco, porque o aluno vê o erro, aceita e continua reproduzindo esse erro. Ele continua passivo nesse processo, o que não pode acontecer. Eu tenho um caso sobre isso pra narrar.

Roberto: Mas não é bem assim. Eu mesmo, depois de algumas situações complicadas, tentei reclamar. Tive que mudar de instituição pra terminar o curso...

Hélton: Também reclamei. Quando estudava na graduação, tinha uma prova única nas disciplinas de Física.

Mediador: Atualmente existe também nas disciplinas de Cálculo.

Hélton: E ninguém passava em Física. Porque eram vários professores corrigindo as provas. Eles não conheciam os estudantes e não levavam em consideração o que o estudante mostrava em sala ou em outras avaliações.

Roberto: Ah! Mas isso aí acontecia até quando não era disciplina unificada e o próprio professor que corrigia.

Hélton: É. Mas a gente fez um movimento com estudantes de outros cursos, de engenharia. Definimos um representante de cada curso e fomos até a Pró-Reitoria de Ensino para abrir uma reclamação formal no Conselho.

Marta: E deu certo?

Hélton: Sim. Deixou de ser nesse formato.

Juninho: Mas, agora, voltou a ser assim em Cálculo.

\section{Episódio 2: "Ser" ou "não ser" professora/professor?3}

Mediador: Parece que a Marta quer falar sobre outro assunto.

Marta: Eu queria falar sobre o perfil do estudante da Licenciatura. Uma questão que eu acho que acontece é que a maior parte dos alunos começa o curso não querendo ser professor.

3 Inspirado no título do artigo: "Ser" ou "não ser" professora/professor? Eis uma questão em busca de respostas (FERREIRA, 2016). 
Mediador: Mas por que acha que isso acontece?

Marta: Eu verifiquei isso em vários lugares que trabalhei com formação de professores. Pouquíssimos eram os que entravam querendo a carreira docente. A realidade é que o estudante que acha que é bom em matemática quer fazer engenharia ou qualquer coisa na área de exatas, menos dar aula. Porque ele sabe que como professor não vai ter retorno financeiro, vai dar aulas na educação básica para alunos que não sabem nem ler.

Juninho: Na verdade, quando iniciamos a graduação não temos a noção de que vamos chegar na escola e o aluno não vai saber ler.

Marta: Pode ser. Mas o que quero destacar é que a maioria chega na Licenciatura em Matemática porque foi o curso para o qual conseguiu passar. Poucos têm aquela vontade de ser professor.

Hélton: Mas eu acho que é durante a graduação que essa vontade tem que crescer. Eu mesmo coloquei Informática como primeira opção no vestibular e Matemática como segunda e passei pra segunda opção. Como era no turno diurno ainda tive que escolher entre Bacharelado e Licenciatura. Escolhi Bacharelado quase que de forma aleatória, pois eu não sabia a distinção precisa entre os dois. Quando a gente é novo não tem esse conhecimento.

Marta: Sim, pois enquanto somos estudantes, não temos muita noção do que é ser professor. Isso porque a gente ainda está num papel de aluno. Têm vários autores que falam disso: que leva um tempo pra passar da condição de aluno para a condição de professor, pois começamos o curso com a mentalidade de aluno. A gente não tem aquela ideia do que é ser professor, pois isso aí se adquiri na convivência com outros pares, com professores, com outros colegas que têm essa vontade de ser professor.

Roberto: Então, no segundo ano da graduação, fui convidado para dar aula no PréVestibular para Negros e Carentes, e foi nesse espaço que comecei a entender a docência. Assim, a experiência de estar dando aula ao mesmo tempo que estava na graduação foi importante pra mim, pois após o primeiro semestre da graduação eu fiquei pensando se aquele ali era o meu lugar.

Mediador: Você acha que a prática foi importante pra você seguir no curso?

Roberto: Sim, claro.

Marta: Eu acho que as disciplinas devem valorizar a prática pedagógica. Voltando à realidade dos estudantes da Licenciatura em Matemática: eles estão ali porque foi o curso que conseguiram passar e muitas vezes são pessoas com bastante dificuldade financeira. Eles começam o curso e logo nos primeiros anos já estão dando aula, pois conseguem emprego em escola ou curso. Assim, pelo fato de conseguirem emprego na área, acham que não precisam da prática de ensino e do estágio supervisionado. 
Pensam assim: "Por que vou precisar da prática se já dou aula?".

Roberto: Mas no meu caso não era um emprego. Eu era voluntário e acho que lá era um espaço interessante para pensar além da prática com os conteúdos matemáticos, mas também em ser professor independentemente da disciplina que vou lecionar.

Marta: Entendi. Porém, minha fala é no sentido de que muitas vezes a prática da sala de aula do ainda estudante da Licenciatura é uma reprodução da prática que ele viu quando era aluno da escola. Eu acho que a universidade deveria ser um espaço pra pensar novas práticas, um ambiente pra pensar outras possibilidades, diferentes daquela que você viu como aluno.

Juninho: Concordo com isso, mas existem espaços na universidade para novas práticas que não são utilizados para esse fim. Por exemplo, as disciplinas pedagógicas que fiz até agora, "sociologia da educação", "psicologia da educação" e "educação brasileira", são dadas a partir de uma perspectiva muito teórica, muitas vezes sem qualquer ligação com a prática. Posso dizer que muito pouco do que vi nessas disciplinas ficou pra mim.

Marta: Essas novas práticas podem vir de algumas maneiras: em materiais ou em conteúdos de disciplinas. Por exemplo, as disciplinas pedagógicas deveriam ser mais direcionadas para o ensino da matemática, no nosso caso. Porque é muito ruim fazer disciplinas como "didática geral", "psicologia", com alunos de todas as licenciaturas. Eu acho que algumas das disciplinas pedagógicas que o Juninho citou tinham que ser pensadas pro caso da matemática em específico, pois existem as dificuldades próprias no ensino de determinados conhecimentos matemáticos.

Mediador: Mas vocês não acham que nessas disciplinas pedagógicas os estudantes do curso podem encontrar, conversar e construir vínculos e conhecimentos com os estudantes de outras licenciaturas?

Marta: Sim. Mas, às vezes, é tanta coisa pra dar conta que chega uma hora que você não consegue pagar tudo. É muita coisa que tem pra atender na Licenciatura em Matemática. Não dando pra tudo, eu deixaria essas disciplinas voltadas pra matemática.

Hélton: Mas, Marta, você falou anteriormente que se adquiri o gosto pela docência na convivência com aqueles que querem ser professor. Já que poucos estudantes do curso têm esse gosto, se não for dando aula durante a graduação em espaços como o que o Roberto descreveu ou nas disciplinas que contam com licenciandos de outras áreas, onde mais será essa convivência?

\section{Episódio 3: Currículo diferenciado ou bacharelado disfarçado?}

Juninho: Mesmo com todas as nossas críticas, eu acho que o curso da UFRJ é bom. Eu 
tive contato com várias pessoas que estudavam Licenciatura em Matemática em outras universidades do Brasil e vi que o currículo da Licenciatura em Matemática daqui é diferenciado. Têm muitos problemas e eu concordo com os que vocês citaram. Por exemplo, as aplicações da matemática em sala de aula são pouco faladas e, quando são, isso ocorre só nas disciplinas de "fundamentos". Além disso, eu também compartilho com o que já disseram sobre a Geometria ser pouco vista no curso.

Roberto: A gente até vê. Eu vi Geometria Euclidiana e Não-Euclidiana, mas sem questionamentos assim: "Por que você tá aprendendo isso?" ou "Por que é importante saber esses conceitos?".

Mediador: Nem nas disciplinas de "fundamentos"?

Roberto: Eu fazia mais as disciplinas no diurno e as três disciplinas de "fundamentos" eram à tarde. Elas tinham um pouco mais de discussão dos conteúdos da Escola, mas eu só percebi uma preocupação com a problemática da sala de aula na educação básica em uma professora dessas disciplinas.

Juninho: Eu vi um pouco dessa preocupação em Fundamentos da Geometria. Porém, só ocorreu nas aulas em que a professora da disciplina convidou uma professora da educação básica. O que eu sinto na Licenciatura em Matemática da UFRJ é que eu tenho que procurar um professor que vá lecionar essas disciplinas e que tenha um olhar diferenciado para o ensino.

Mediador: Juninho, uma coisa me chamou atenção quando você disse que o currículo do curso na UFRJ comparado com o de outras universidades brasileiras é diferenciado. Você pode falar mais sobre essa comparação?

Juninho: Então, durante a graduação eu fiz um intercâmbio no exterior e pude conviver com diversas pessoas que faziam Licenciatura em Matemática em outras universidades federais brasileiras e estavam lá no intercâmbio também. Eu me surpreendi, pois quando eles falavam dos currículos das universidades deles, percebia que eram muito mais voltados à matemática pura. Muito pouco se falava sobre o ensino. Até os docentes da universidade que eu fazia o intercâmbio elogiaram o currículo da UFRJ, porque lá já tem outra metodologia: tem que se formar primeiro como bacharel em matemática e depois fazer um mestrado em ensino para poder dar aula na escola.

Roberto: Ah! Nessas universidades deve ser como no curso diurno da UFRJ, que não tem separação entre bacharelado e licenciatura. Se eu tivesse feito o curso todo no turno diurno, eu teria feito um curso de licenciatura com nenhuma aula voltada para aquilo que eu iria fazer em si, que era dar aula. Tanto que pra eu me formar na UFRJ ficaram faltando 3 disciplinas, que eu digo que são do Bacharelado: Análise Real, Cálculo 3 e Física 3.

Hélton: Eu acho importante ter algumas disciplinas como Análise Real e as 
Geometrias, por exemplo, e entendo que elas são da Licenciatura também. Elas foram muito importantes para minha formação, pois me deram bagagem para poder ensinar. Não digo pelos professores dessas disciplinas, mas pelas ferramentas que elas me deram para a prática docente.

Marta: Isso eu concordo. Como fiz bons cursos de Geometria na graduação, já terminei a licenciatura com um emprego em escola particular. Porque nas escolas particulares famosas pouca gente queria dar aula de geometria por insegurança. Eu tinha esse diferencial.

Hélton: Sem contar que o diploma da UFRJ dá uma chancela, tem um peso.

Roberto: Como já falei aqui, eu saí da UFRJ e fui para uma universidade privada. De fato, eu lembro que quando cheguei lá e disse que vinha da UFRJ fui tratado quase como um popstar. Me perguntavam: "O que você tá fazendo aqui?". Eu queria terminar a graduação porque tinham concursos públicos para professor naquele ano e eu desejava um lugar que eu terminasse rápido. Acabei ficando um ano lá, mais do que pretendia. Foi um ano muito rico, sem querer desmerecer todos os que passei na UFRJ.

Mediador: Por que considera que foi um ano importante?

Roberto: Porque me colocaram para dar monitoria pra turmas de pedagogia. Nesse espaço fui levado a refletir, por exemplo, sobre o porquê dos procedimentos matemáticos das operações. "O que significa o "pedir emprestado'?". Isso me permitiu fazer um bom debate com o pessoal de pedagogia e até com os colegas de matemática. O curso de lá tinha um laboratório de matemática e disciplinas voltadas para o desenvolvimento de material para sala de aula. Tive contato com vários desses materiais.

Juninho: Agora também tem essa disciplina de "Laboratório" na Licenciatura da UFRJ. Acho que passou a ter na última mudança curricular. Com certeza ainda tem muito pra melhorar, mas já vejo uma melhora significativa em relação aos currículos antigos.

Roberto: Que bom! Porque na minha época não tinha. Quase não vi nada disso durante o curso. Só quando fiz a disciplina "prática de ensino" à noite que tive algo parecido. Era um professor substituto e o que ele fez foi dividir tópicos do conteúdo de matemática na educação básica entre os alunos. Aí, cada um tinha que dar uma aula sobre o tópico escolhido. Mas, no geral, o viés era bem pouco de licenciatura, ocorria bem pouco isso.

Mediador: Na instituição privada você identificava mais espaços como esse?

Roberto: Sim, mesmo em disciplinas de matemática pura e aplicada os professores diziam: "isso aqui você vai precisar quando for ensinar tal coisa". Alguns, mesmo sendo professores da faculdade, também eram professores da educação básica. Então eles 
tinham essa experiência... Entendeu? Isso fez uma diferença muito grande. Então, pra mim, quando fiz essa mudança de curso foi um choque muito grande, mas foi muito bom.

\section{Comentários e Considerações}

Apresentamos aqui considerações que chamaremos de preliminares por entendermos que é possível traçar conclusões distintas das nossas, seja em relação à questão de pesquisa central, seja sobre as questões secundárias que emergiram. Como uma tentativa inicial de revelar como estudantes e egressos de um curso de Licenciatura em Matemática entendem que são constituídos pelo currículo e podem participar da construção do mesmo em sua formação docente, teceremos comentários sobre os episódios, relacionando-os com a discussão teórica que apresentamos no início deste artigo. Esses comentários não esgotam o debate sobre o tema e se localizam em um contexto muito específico, em que a natureza do trabalho, a relação dos autores com a instituição, as escolhas teórico-metodológicas e a literatura de pesquisa na qual nos embasamos moldaram tanto a produção dos dados como as considerações que fazemos a seguir.

Com o primeiro episódio, desejamos explicitar nas falas iniciais o entendimento de alguns dos participantes de que: os estudantes do curso têm responsabilidade em relação ao currículo de sua formação. Entendemos que tal afirmação coloca os estudantes como participantes do currículo de sua própria formação e dialoga com as discussões teóricas no campo do currículo, que reconhecem que este é construído a partir de múltiplas narrativas (SILVA, 2014) ou é transformado a partir de discursos situados em seus contextos (OLIVEIRA, LOPES, 2011). Por isso, no primeiro parágrafo desta seção fizemos uma alteração na redação da questão de pesquisa, incluindo o termo "entendem que" - o que reflete um direcionamento da investigação para uma perspectiva que não considera os estudantes como sujeitos que apenas "sofrem" influências, mas que as entendem e agem a partir delas. No mesmo episódio, a passividade apontada por Hélton quando os estudantes se 
deparam com situações complicadas configurou-se, propositalmente, em um ponto de inflexão, uma vez que: antes dessa declaração ocorrem várias referências às discussões teóricas sobre formação docente e currículo que destacamos; depois da mesma, iniciam-se algumas divergências.

Antes desse ponto de inflexão, verificamos nas falas uma proximidade entre versões curriculares de épocas distintas, que se manifesta nas discussões sobre os modelos indicados, respectivamente, por Moreira (2012) e por Fiorentini e Oliveira (2013) como hegemônicos nos períodos pesquisados: 3+1 e Quase Tricotomia. Além disso, também vemos, nessa parte do episódio, pontos referentes aos docentes, como o que se apresenta nas falas de Juninho e de Hélton em sequência, ao indicarem a ação do professor formador no processo de avaliação de uma disciplina na graduação como possível influência para a prática do futuro professor na educação básica. Esse ponto evidencia o currículo não só como sendo constituído de textos, como programas curriculares e ementas de disciplinas, mas também de práticas e discursos, como destacam Oliveira e Lopes (2011).

Passando à parte posterior ao ponto de inflexão e entendendo o currículo como dependente de várias variáveis, a fala de discordância de Roberto revela a singularidade do percurso do estudante durante sua formação, inclusive em possibilidades que excedem o programa curricular do curso. Nesse sentido, retomamos a concepção de currículo como currere, a qual destaca o protagonismo da ação do estudante (SILVA, 2014), no caso de Roberto, revelado na busca por um (per)curso que melhor atendesse suas expectativas. Esse processo de ação discente também está no caso narrado por Hélton, ao relatar a movimentação de estudantes de vários cursos para promover modificações nas formas de avaliação e funcionamento de disciplinas. Uma interpretação das responsabilidades discentes em relação ao currículo do curso, que trazemos à luz no episódio 1, é a que entende a passividade como uma escolha, pois nela a não-ação não se configura em uma posição neutra sobre sua formação, uma vez que esta pode constituir suas práticas docentes futuras. 
No episódio 2, ao encerrarmos com a constatação e a questão apresentadas por Hélton em relação às falas de Marta, almejamos não só deixar para o leitor a construção da resposta à pergunta proposta, como também reafirmar as contradições nos discursos dos personagens. Porém, a questão principal que desejamos evidenciar a partir dos diálogos é: em que tempos e/ou espaço do curso o estudante da Licenciatura em Matemática se percebe como um futuro professor de matemática? $\mathrm{O}$ perfil do estudante da Licenciatura em Matemática, o status e as condições de trabalho do professor, a demora na passagem da condição de aluno para a de professor são apontamentos que se relacionam e foram citados pelos personagens para justificar uma falta de autopercepção dos estudantes como futuros docentes. Entendemos que esses argumentos compõem um conjunto de fatores que sofrem influências de concepções de formação de professores e políticas públicas relativas à educação básica. Entretanto, outros fatores estão no cerne da discussão sobre o conhecimento proveniente da prática do professor e também se relacionam com essas concepções sobre formação docente.

Assim, a discussão sobre a prática docente aparece nesse episódio na fala de Marta, ao dizer que os estudantes acreditam não necessitarem "da prática de ensino e do estágio supervisionado", por já darem aulas durante a graduação. De fato, as ações em salas de aula na educação básica ou em projetos alternativos de educação durante o curso são entendidas por outros personagens como importantes para sua autopercepção em relação à profissão docente. Tal posição nos remete ao relato de Marta ao observar que a prática do estudante em sala de aula durante o curso de Licenciatura pode ser uma "reprodução da prática que ele viu quando era aluno da escola". Como destacam Cochran-Smith e Lytle (1999), as práticas de professores mais experientes podem determinar, mesmo com separação temporal, a aprendizagem docente - o que, não tem, necessariamente, um caráter negativo. Porém, as autoras alertam que esse conhecimento prático localizado, por vezes isolado, pode impedir a problematização dos fazeres docentes marcados por uma rotina repetitiva de sala de aula. 
$\mathrm{Na}$ esteira desse debate, outro ponto sobre o conhecimento prático na formação do professor de matemática foi suscitado: que espaços devem discutir a prática no curso de Licenciatura em Matemática? Nesse contexto, falas de dois personagens revelam críticas às disciplinas ditas pedagógicas, oferecidas pela Faculdade de Educação, por aspectos distintos: um calcado na distância entre teoria e prática, caracterizando essas disciplinas como muito teóricas e pouco aplicadas; e outro centrado na falta de foco dessas disciplinas no ensino da matemática. Essa discussão tem paralelos com a pesquisa acerca do lugar da prática na Licenciatura. Seja em um bloco de disciplinas dentro da quase tricotomia que sugere a separação da formação em disciplinas de matemática, didático-pedagógicas e de prática profissional (FIORENTINI e OLIVEIRA, 2013), seja permeando todo o curso a partir da prática como componente curricular (BRASIL, 2015), os pontos trazidos pela literatura de pesquisa já não colocam as disciplinas didático-pedagógicas com exclusiva responsabilidade em relação à abordagem dos saberes da prática. Assim, entendemos que as críticas trazidas pelos personagens indicam ainda uma lógica dicotômica presente nos currículos do modelo 3+1 (MOREIRA, 2012), presa ao binarismo entre os conhecimentos específico e pedagógico. Esses posicionamentos ilustram certa "carência de identidade" dos currículos das Licenciaturas em Matemática, o que pode dificultar que o estudante se perceba como futuro professor.

O episódio 3 nos permitiu acessar diversos sentidos e afetos que o currículo do curso provoca nos estudantes durante suas trajetórias. Ora um currículo diferenciado, ora um currículo próximo do bacharelado, nessa régua não estão em jogo somente as avaliações que rotulam o curso como um $3+1$ (MOREIRA, 2012), ou como uma legítima formação profissional para a docência (TARDIF, 2013; NÓVOA, 2009), ou, ainda, como uma hibridez das duas concepções. Aqui também se evidenciam as relações com a instituição, com a profissão e com os sujeitos presentes nos vários contextos de formação em que os personagens transitam. A avaliação comparativa positiva de Juninho em relação ao currículo do curso, o encontro de Roberto com um outro 
lugar de formação docente, o destaque dado ao status da instituição por Hélton e a valorização do conhecimento matemático destacada por Marta são pontos presentes no diálogo que exemplificam os sentidos e afetos que, conforme Barbosa (2015) destaca, foram tomados pelos personagens, apresentando-se, por vezes, de maneira contraditória aos seus discursos.

Ao destacar as diferenças entre os currículos de formação de professores de matemática no Brasil e no exterior, inicialmente nos remetemos à discussão nos episódios anteriores sobre modelos dependentes do bacharelado. Porém, quando essas diferenças se somam à comparação entre o currículo da UFRJ e o de uma instituição privada brasileira a partir das falas de Roberto, alcançamos outro debate já antecipado por CochranSmith e Lytle (1999), ao combinarem as palavras conhecimento e prática utilizando três preposições diferentes (para, na e da) para definirem concepções da formação docente. Seria o modelo de formação da instituição estrangeira calcado na concepção de conhecimento-para-prática, que tem o conhecimento acadêmico como único saber de referência para formação de professores? Será que o próprio currículo da Licenciatura em Matemática da UFRJ no turno diurno, narrado por Roberto, está nessa concepção? Estariam também os cursos das outras universidades brasileiras, citados por Juninho, incluídos nessa concepção? Por outro lado, o currículo da instituição privada, que Roberto destacou, apresenta traços da concepção de conhecimento-naprática, que se referencia na experiência da prática, mas sem necessariamente problematizá-la? E o currículo do curso de Licenciatura em Matemática da UFRJ noturno, onde se encaixa?

Não propomos respostas precisas para essas questões, mesmo porque não temos elementos e nem é nosso objetivo analisar os currículos da formação inicial de professores de matemática de outras instituições. Inclusive, em relação ao currículo da Licenciatura em Matemática da UFRJ, entendemos que trazemos aqui, a partir dos olhares discentes, narrativas em disputa, seja pelo caráter subjetivo do currículo, sugerido por Silva (2014) ao interpretá-lo como percurso, seja pela complexidade destacada pelo mesmo autor e em 
teorias pós-críticas (LOPES, 2013). Tal complexidade se manifesta, por exemplo, nas falas que atrelam a cada um dos turnos do curso na UFRJ um currículo distinto. Nos documentos oficiais (UFRJ, 2017), há apenas um programa curricular do curso, que serve aos turnos diurno e noturno. Porém, entendendo currículo como constituído de práticas e de discursos (OLIVEIRA e LOPES, 2011), as práticas (institucionais, docentes e discentes) destacadas pelos personagens evidenciam diferenças profundas entre os currículos praticados. Os discursos, não só os dos discentes, mas também os institucionalizados e os dos docentes, possibilitam o acesso a versões que, se não esclarecem pontos polêmicos, evidenciam relações entre o contexto do curso de Licenciatura em Matemática da UFRJ e discussões teóricas sobre formação de professores e currículo.

Retomando a discussão sobre as concepções de formação de professores reveladas no episódio 3, trazemos à cena a terceira concepção denotada por Cochran-Smith e Lytle (1999) como conhecimento-da-prática - não na tentativa de usá-la para rotular algum curso de formação docente citado, mas na busca por um debate a partir de elementos destacados pelos personagens nos episódios. Sob essa concepção, os conhecimentos para o ensino não podem ser dissociados em teóricos e práticos, e são produzidos quando os professores consideram suas próprias práticas como objeto de investigação intencional. Assim, no terceiro episódio identificamos, em falas como "mesmo sendo professores da faculdade, também eram professores da educação básica” ou "só ocorreu nas aulas em que a professora da disciplina convidou uma professora da educação básica”, relações entre prática e teoria em situações que dão centralidade à ação docente na escola. Consideramos que pode haver nesse destaque o entendimento, ainda que velado, da separação entre teoria e prática, sendo a última associada apenas ao fazer docente na escola básica. Porém, diferente do que emergiu no episódio 2 , em falas que ressaltam a importância da prática docente durante a formação inicial dentro ou fora do curso, as experiências individuais e as ações de professores mais experientes não aparecem como os únicos definidores da aprendizagem docente. Essa 
interpretação se deve ao fato das falas que indicamos acima direcionarem a ação prática dentro de um contexto que considera a figura do professor da educação básica em disciplinas que compõem o currículo do curso, e não apenas em ações em contextos externos ou no estágio. Isto é, identificamos em episódios distintos um deslocamento do que se entende como conhecimento prático, posicionado externamente ao currículo no segundo episódio e internamente ao currículo no terceiro.

Entendemos, assim, que práticas docentes são intencionais e não desconsideram o contexto, pois são atravessadas por reflexões que determinam a produção de um conhecimento situado na prática, bem como por teorias produzidas na academia (COCHRAN-SMITH e LYTLE, 1999). Como Nóvoa (2009), compreendemos que deve-se incorporar a prática na formação docente, pois os professores produzem o conhecimento no locus da prática. Não acreditamos que seja essa a posição dos participantes da roda de conversa, em geral. Porém, identificamos elementos que se aproximam de tal concepção. Não como uma resposta à questão de pesquisa proposta, mas como um apontamento para pesquisas futuras, concluímos que os olhares discentes para suas formações se relacionam com aspectos do currículo que dialogam com a prática docente que desempenham ou desempenharão na escola. Isto é, para além de qual disciplina deve ou não figurar no curso, as preocupações giram em torno de como os saberes desenvolvidos e mobilizados se relacionam com a prática do professor de matemática.

\section{Referências}

BARBOSA, J.C. Formatos insubordinados de dissertações e teses na Educação Matemática. In: D'AMBROSIO, B.S.; LOPES, C.E. (Orgs). Vertentes da subversão na produção científica em educação matemática. Campinas: Mercado de Letras, 2015.

BRASIL. Parecer CNE-CP n ${ }^{0}$ 02, de 09 de junho de 2015. Institui Diretrizes Curriculares Nacionais para a Formação Inicial e Continuada dos Profissionais do Magistério da Educação Básica. Brasília: Conselho Nacional de Educação, 2015.

COCHRAN-SMITH, M.; LYTLE, S. Relationships of knowledge and practice: teacher learning in communities. Review of Research in Education, London: Sage, n.24, p. 
249-305, 1999.

COSTA-NETO, C.; GIRALDO, V. Do $3+1$ à prática como componente curricular: uma narrativa possível sobre o currículo da formação inicial de professores de matemática na UFRJ. Revista Paranaense de Educação Matemática, v. 8, n. 17, p. 369-394, 2019.

CURY, F.; SOUZA, L.; SILVA, H. Narrativas: um olhar sobre o exercício historiográfico na Educação Matemática. Bolema, v. 28, n. 49, p. 910-925, 2014.

GABRIEL, C. T. Conhecimento Científico e Currículo: Anotações sobre uma articulação impossível e necessária. Revista Teias, v. 14, n. 33, p. 44-57, 2013.

FERREIRA, L. S. "Ser" ou "não ser" professora/professor? Eis uma questão em busca de respostas. Educ. rev. [online]. n.59, p.175-192, 2016.

FIORENTINI, D.; OLIVEIRA, A. T. C. C. O lugar das matemáticas na Licenciatura em Matemática: que matemáticas e que práticas formativas? Bolema, v. 27, n. 47, p. 917-938, 2013.

LIMA, F. H. Um método de transcrições e análise de vídeos: a evolução de uma estratégia. Anais do VII Encontro Mineiro de Educação Matemática, 2015.

LOPES, A. Teorias Pós-Críticas, Política e Currículo. Educação, Sociedade e Culturas, n. 39, p. 7-23, 2013.

MOREIRA, P.C. $3+1$ e suas (in)variantes: reflexões sobre as possibilidades de uma nova estrutura curricular na licenciatura em matemática. Bolema, n. 26, p. 11371150, 2012.

NARDI, E. Where form and substance meet: Using the narrative approach of restorying to generate research findings and community rapprochement in (university) mathematics education. Educational Studies in Mathematics, n. 92, v. 3, p. 361-377, 2016.

NÓVOA. A. Para uma formação de professores construída dentro da profissão. Professores: imagens do futuro presente. Lisboa: Educa, p. 25-46, 2009.

OLIVEIRA, A.; LOPES, A. A abordagem do ciclo de políticas: uma leitura pela teoria do discurso. Cadernos de Educação, Pelotas, n. 38, p. 19-41, 2011.

PEMAT. Apresentação. In: IV Seminário da Licenciatura (4º 2016 , Rio de Janeiro, Brasil). Seminário de Licenciatura. Rio de Janeiro, Brasil, Programa de PósGraduação em Ensino de Matemática (PEMAT), UFRJ, 2016.

POWELL, A.; FRANCISCO, J.; MAHER, C. Uma Abordagem à Análise de Dados de Vídeo para Investigar o Desenvolvimento das Idéias Matemáticas e do Raciocínio de Estudantes. Tradução de Antônio Olimpio Junior. Boletim de Educação Matemática - BOLEMA. Rio Claro, n. 17, v. 21, 2004. 
SHULMAN, L. S. Those Who Understand: Knowledge Growth in Teaching. Educational Researcher, n. 15, v. 2, p. 4-14, 1986.

SILVA, M. A. Currículo como Currere, como Complexidade, como Cosmologia, como Conversa e como Comunidade: contribuições teóricas pós-modernas para a reflexão sobre currículos de matemática no ensino médio. Bolema. Boletim de Educação Matemática, Rio Claro, n. 28, v. 49, p. 516-535, 2014.

TARDIF, M. A profissionalização do ensino passados trinta anos: dois passos para a frente, três para trás. Educ. Soc. [online], n. 34, v. 123, p. 551-571, 2013.

UFRJ. Grades curriculares do curso de Licenciatura em Matemática. In: Sistema Integrado de Gestão Acadêmica. Disponível em: <https://siga.ufrj.br/sira/intranet>. Acesso em: 14 jul. 2017, 2017.

Recebido em janeiro de 2020.

Aprovado em março de 2020. 